\title{
Development and validation of a snow albedo algorithm for the MODIS instrument
}

\author{
Andrew G. Klein, ${ }^{1}$ Julienne Stroeve ${ }^{2}$ \\ ${ }^{1}$ Department of Geography, MS 3147 Texas A E M University, College Station, TX 77843-3147, U.S.A. \\ ${ }^{2}$ National Snow and Ice Data Center, Cooperative Institute for Research in Environmental Sciences (CIRES), \\ University of Colorado, Boulder, CO 80309-0449, U.S.A.
}

\begin{abstract}
A prototype snow albedo algorithm has been developed for the Moderate Resolution Imaging Spectroradiometer (MODIS). It complements existing MODIS products by providing albedo measurements for areas mapped as snow on a global daily basis by MODIS. Cloud detection and atmospheric correction are accomplished using existing MODIS products. Models of the bidirectional reflectance of snow created using a discreteordinate radiative transfer (DISORT) model are used to correct for anisotropic scattering effects over non-forested surfaces. Initial algorithm validation is undertaken through comparisons with broadband albedo measurements made at the U.S. National Oceanic and Atmospheric Administration (NOAA) Surface Radiation Budget Network (SURFRAD) site in Fort Peck, MT. In situ SURFRAD albedo measurements are compared to daily MODIS snow albedo retrievals for the period 21-26 November 2000 created from five narrow-tobroadband albedo conversion schemes. The prototype MODIS algorithm produces reasonable broadband albedo estimates. Maximum daily differences between the five MODIS broadband albedo retrievals and in situ albedo are $15 \%$. Daily differences between the "best" MODIS broadband estimate and the measured SURFRAD albedo are $1-8 \%$. However, no single conversion scheme consistently provides the closest albedo estimate. Further validation and algorithm development using data from North America and Greenland is ongoing.
\end{abstract}

\section{INTRODUCTION}

Snow is one of the Earth's fastest-changing land covers and is an important component in the Earth's climate system across all spatial scales (Kukla, 1981). Snow albedo strongly affects shortwave energy fluxes, as has been demonstrated for the Greenland ice sheet (Nolin and Stroeve, 1997). Accurate estimates of snow albedo are critical inputs into local- or basinscale snowmelt runoff and energy-balance models. Because snow can cover a significant amount of the globe, it not only influences local- and regional-scale processes but also affects the Earth's global heat budget (Barnett and others, 1989).

Satellites have been used extensively to retrieve a number of snow properties including the object of this research, snow albedo (König and others, 2001), which can change rapidly in space and in time. The albedo of newly fallen snow often exceeds $80 \%$, but can decrease to $20-40 \%$ within 2 weeks (O’Neill and Gray, 1973; Winther, 1993a,b). Snowfall and snowmelt events can also cause large changes in snow albedo in a matter of hours. Satellites provide an efficient means to monitor both spatial and temporal variability in snow albedo over large areas. Consequently, satellite determination of snow reflectance and albedo has a long history for snow and glaciers (e.g. Robinson and Kukla, 1985; Hall and others, 1989; Winther, 1993a, b; Knap and Oerlemans, 1996; Stroeve and others, 1997; Reijmer and others, 1999) and for sea ice (De Abreau and others, 1994; Lindsay and Rothrock, 1994; Jin and Simpson, 2000).

Building on this work, a prototype clear-sky snow albedo algorithm for the NASA Moderate Resolution Imaging
Spectroradiometer (MODIS) instrument has been developed (Klein and Hall, 1999; Klein and others, 2000). The algorithm is designed to provide global daily snow albedo measurements for areas mapped as snow by the MODIS snow-mapping algorithm. The albedo algorithm may be extended to encompass areas identified as sea ice by MODIS. Currently, MODIS data are being used to map snow-cover extent globally at $500 \mathrm{~m}$ resolution on a daily basis using an automated snow-mapping algorithm (Hall and others, 1995, 1998; Klein and others, 1998), and sea ice is mapped globally at $1 \mathrm{~km}$ (Riggs and others, 1999). These daily MODIS products, as well as spatially and/or temporally composited products, are available from the U.S. National Snow and Ice Data Center at nsidc.org.

The prototype algorithm was developed prior to the launch of the MODIS instrument using data obtained from the MODIS Airborne Simulator (MAS) (Klein and others, 2000). Qualitatively, the MAS-based algorithm appeared to perform as envisioned. However, lack of concurrent field observations during MAS overflights limited the ability to perform quantitative assessments of the algorithm's performance.

Beginning in November 2000, provisional MODIS data products needed as input into the algorithm became available with quality suitable for further algorithm development and validation. These MODIS-based development and validation efforts are designed to improve the prototype's performance prior to implementation of a fully functional production algorithm. Presented here is a brief description of the current MODIS snow albedo prototype algorithm and comparisons between retrieved MODIS snow albedo estimates and in situ broadband albedo measurements made 
at the Fort Peck, MT, Surface Radiation Budget Network (SURFRAD) site during the period 21-26 November 2000. These comparisons are being used to guide the continued development of this MODIS snow albedo algorithm.

\section{MODIS}

MODIS is a polar orbiting, across-track scanning spectroradiometer that images the high latitudes on a daily basis, making it well suited for observing the Earth's snow- and ice-covered regions. A MODIS instrument was launched aboard NASA's Terra satellite on 18 December 1999, and a second MODIS instrument is scheduled for launch aboard the Aqua satellite no earlier than December 2001. MODIS has seven spectral bands in the $0.4-2.5 \mu \mathrm{m}$ range designed for observing the land surface with spatial resolutions of $250 \mathrm{~m}$ (bands 1 and 2) or $500 \mathrm{~m}$ (bands 3-7). However, limitations on available digital-elevation and land-cover information will require that the snow albedo product be produced at $1 \mathrm{~km}$ resolution.

\section{THE MODIS SNOW ALBEDO PROTOTYPE ALGORITHM}

\section{Background}

The MODIS snow albedo prototype algorithm has been detailed elsewhere (Klein and Hall, 1999; Klein and others, 2000), so only a cursory overview is presented here. The design goal of the algorithm is to produce daily albedo measurements of the Earth's snow-covered areas under clear-sky conditions. Albedo is typically defined as the ratio of reflected to incident irradiance measured in a surfaceparallel plane. The albedo determined from MODIS is more correctly termed a directional-hemispherical reflectance, as the incident irradiance is considered a directional collimated beam and the reflected radiance is integrated over the upward hemisphere. Measuring snow albedo from MODIS requires converting MODIS top-of-atmosphere (TOA) radiances, measured over a set of relatively narrow spectral intervals, into a broadband albedo measure for the entire shortwave infrared (IR) portion of the spectrum $(0.4-3.0 \mu \mathrm{m})$. Conversion of MODIS TOA radiances into albedo requires the following adjustments to be made:

(1) Calibration of the satellite sensors

(2) Correction for atmospheric effects

(3) Correction for anisotropic reflection at the surface considering the slope and aspect of the surface

(4) Calculation of a spectrally integrated albedo.

The prototype MODIS snow albedo algorithm draws heavily on existing snow albedo research in an effort to produce an effective state-of-the-art algorithm with limited development time. In particular, the work of Stroeve and others (1997) provides a solid basis for the construction of a global snow albedo algorithm, especially in the area of correction for anisotropic scattering from snow-covered surfaces. A discrete-ordinate radiative transfer (DISORT) model developed by Stamnes and others (1988) is used to correct for anisotropic scattering effects over non-forested surfaces and considers local slope and aspect in the correction.

The prototype algorithm is designed to operate in the current MODIS production environment. This requires it to be as computationally frugal as possible, but does allow for existing MODIS data products to be utilized as algorithm input. Compared with other instruments, MODIS has the benefit that data provided to the science community will be extensively calibrated (Barbieri and others, 1997).

Atmospheric correction will be accomplished via the MODIS land-surface reflectance product (MOD09) (Vermote and Vermeulen, 1999). As the algorithm has been designed primarily for atmospheric correction over vegetation, its performance over snow may not be ideal. In particular, the method used to retrieve aerosols from MODIS data for use in atmospheric correction only works over dense vegetation. Over bright surfaces like snow, aerosols typically have a darkening effect, and depending on aerosol type and optical depth, they can alter TOA reflectances in the visible wavelengths by as much as 20\% (Nolin and Stroeve, 1997). Thus, atmospheric correction remains a potential limitation.

A suite of MODIS BRDF/albedo products (MOD43) already exists. These products provide measurements of the bidirectional reflectance distribution function (BRDF) and a set of broadband albedo measures using multiple MODIS, and eventually Multi-angle Imaging Spectroradiometer (MISR), measurements taken over 16 day periods (Lucht and others, 2000). A sophisticated inversion approach is used to create satellite-derived measures of BRDF suitable for modeling studies. However, the rapidity with which the albedo of snow-covered surfaces changes limits the usefulness of these 16 day products over snow.

\section{Implementation}

Figure 1 details the algorithm and its inputs. Because the MOD09 surface reflectance product is not readily available at the swath (image) level, the prototype utilizes MODIS

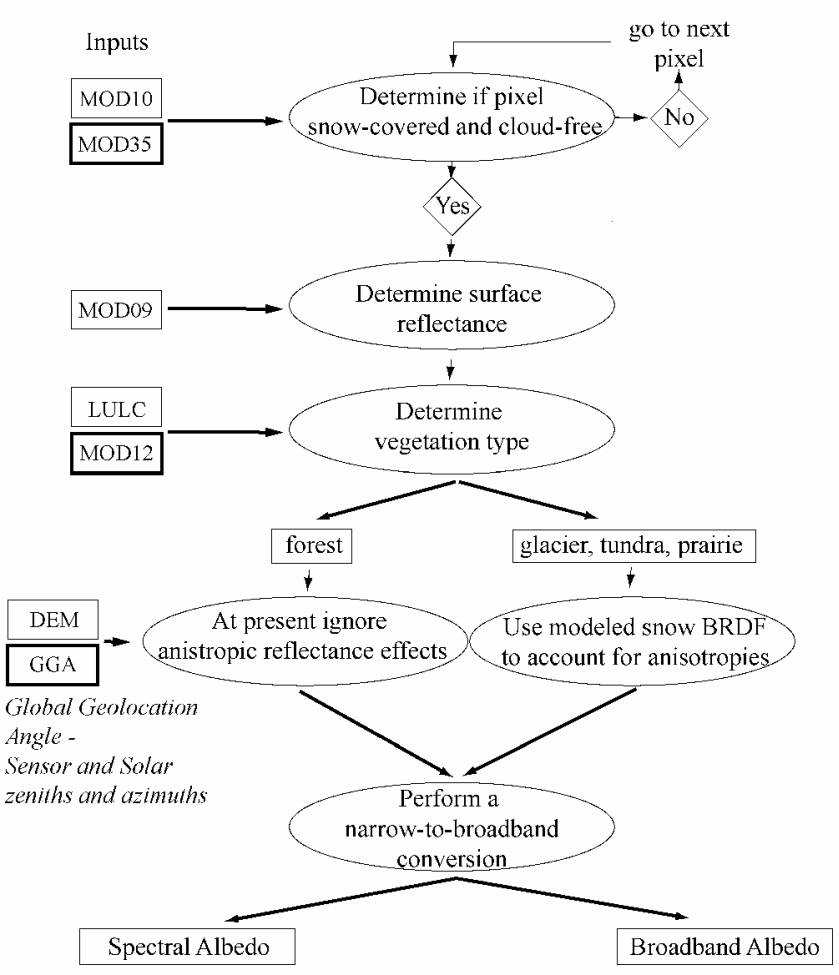

Fig. 1. Flow chart showing the design of, and inputs to, the prototype snow albedo algorithm. MODIS inputs are shown in the boxes on the left, with future inputs italicized. 
Level 2G daily products as inputs (see http://modis-land. gsfc.nasa.gov/products/ for product descriptions). Each Level $2 \mathrm{G}$ product represents a $2.5^{\circ} \times 2.5^{\circ}$ tile of MODIS observations in an integerized sinusoidal (ISIN) equal-area map projection developed specifically for MODIS. For each 250,500 or $1000 \mathrm{~m}$ cell in the tile, all MODIS observations for that day that cover at least part of each cell are recorded. While each cell may contain multiple observations, only the "best" observation, i.e. the MODIS observation that covers the greatest percentage of the cell, is currently used in the albedo determination.

Albedo will only be determined for areas identified as cloud-free by the MODIS cloud mask (MOD35) (Ackerman and others, 1997) and as snow-covered by the MODIS snowmapping algorithm (MOD10) (Hall and others, 1998). Because these two products are not available as Level $2 \mathrm{G}$ products, the prototype utilizes an adaptation of the MODIS snow-mapping algorithm to create snow maps directly from the MOD09 surface reflectances. Cloud information carried in the MODIS/Terra Surface Reflectance Quality Daily L2G Global $1 \mathrm{~km}$ ISIN Grid is used in lieu of the actual MOD35 product. However, this product does contain cover information derived from the MOD35 cloud mask. Once a pixel has been identified as snow-covered and cloud-free, atmospherically corrected surface reflectances are retrieved from the MODIS/Terra Surface Reflectance Daily L2G Global 500 m ISIN Grid. The four MODIS $500 \mathrm{~m}$ pixels comprising a $1 \mathrm{~km}$ pixel are then averaged, ignoring missing data.

Snow is a non-Lambertian reflector, and is in fact a strongly forward-scattering medium. While most satellitederived albedo studies have not corrected for the anisotropic reflectance of snow (König and others, 2001), failure to do so can lead to errors in estimated albedo (Stroeve and others, 1997). Because MODIS samples only a small angular portion of the total energy reflected from the surface, the angular surface reflectance measurements must be converted to hemispherical quantities. This is especially important for MODIS since data used in the albedo calculations may be imaged at angles up to $45^{\circ}$ from nadir and at high solar zenith angles. To correct for these anisotropic scattering effects, knowledge of the BRDF (Nicodemus and others, 1977) is required.

The prototype algorithm utilizes a state-of-the-art approach in correcting for anisotropic scattering effects. This correction is accomplished by normalizing the BRDF by the spectral albedo to create an anisotropic response function (ARFor $f$ ). The ARF is used to adjust the surface reflectances in each spectral band, making it possible to derive a spectral albedo from a single satellite measurement. Values of $f>1$ indicate that the reflectance observed at a particular combination of solar zenith angle, sensor zenith angle and relative azimuth between the sensor and the sun is greater than the spectral directional hemispherical albedo. Values of $f<1$ indicate the measured reflectance is less than the spectral directional hemispherical albedo.

A DISORT approach (Stamnes and others, 1988) has been applied by several investigators to model snow BRDF (Fily and others, 1997; Nolin and Stroeve, 1997; Stroeve and others, 1997). The optical properties needed for the DISORT model include snowpack optical thickness, single scattering albedo and an asymmetry parameter or a description of the scattering phase function. These parameters can be calculated from Mie theory using the refractive indices for ice
180

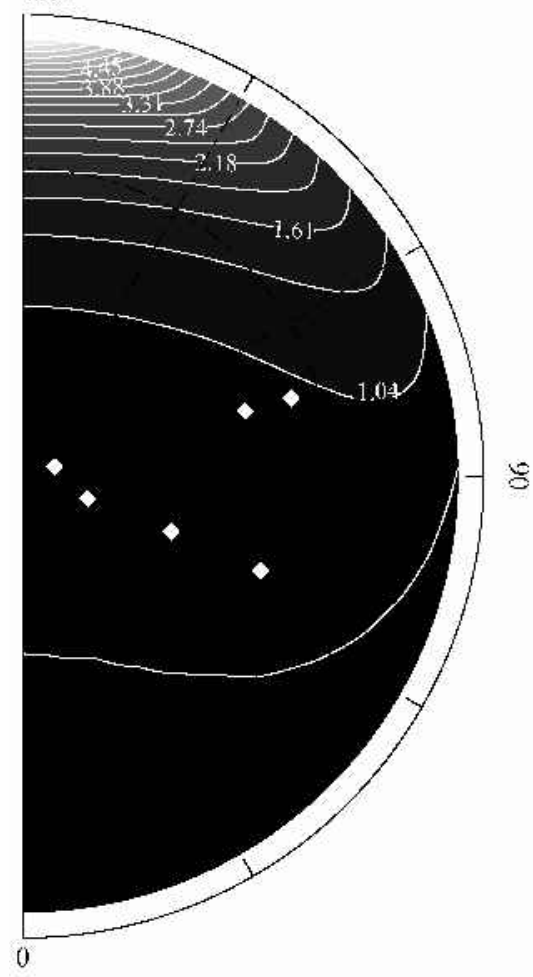

MODIS band 1

$(0.620-0.670 \mu \mathrm{in})$
180

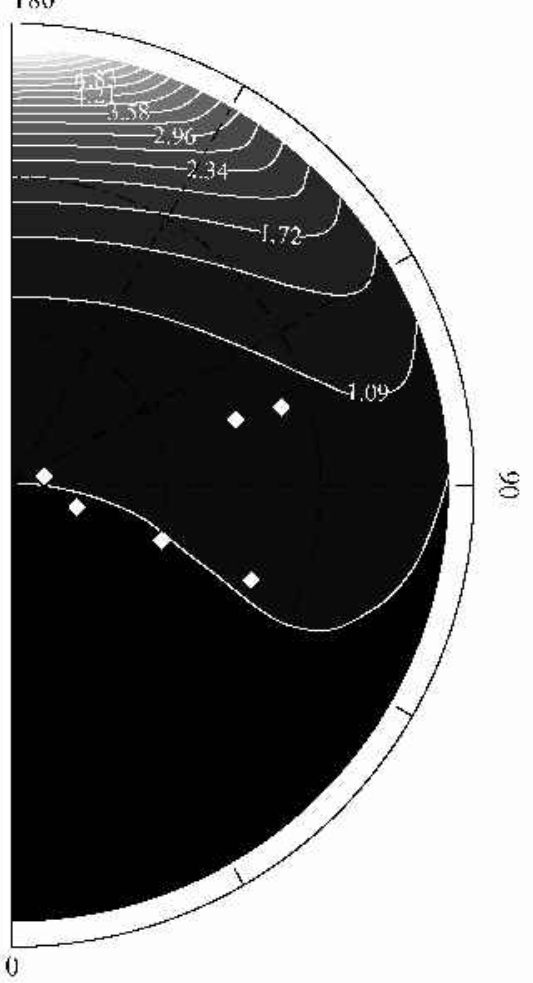

IOLIS band 2

$(0.841-0.876 \mu \mathrm{n})$

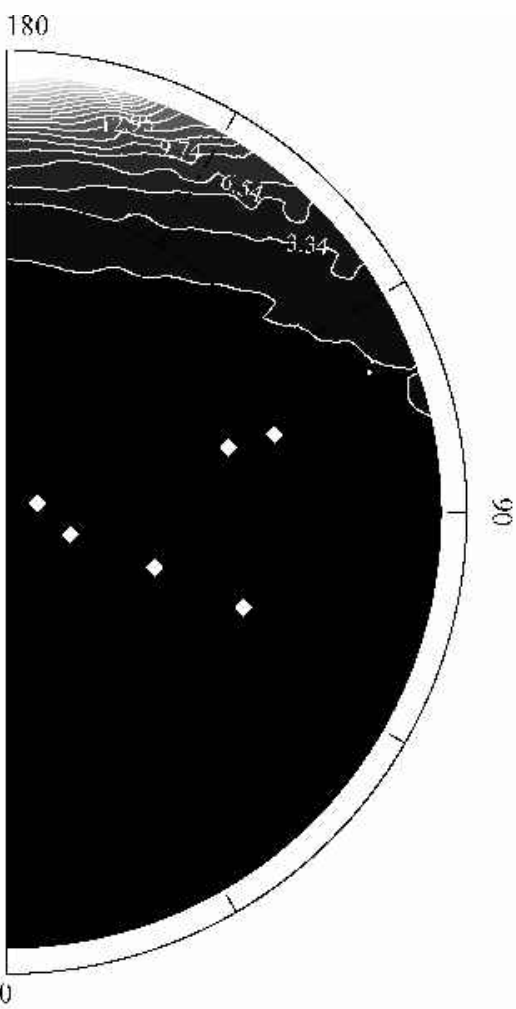

MODIS band 6

$(1.628-1.652 \mu \mathrm{ml})$

Fig. 2. Anisotropic reflectance factors ( $f$ ) for three MODIS bands at a solar zenith angle of $70^{\circ}$, and an optically equivalent grain-size of $250 \mu \mathrm{m}$. The distance from the origin indicates sensor zenith angle, while the direction indicates the relative azimuth between the sensor and the satellite (at $180^{\circ}$ the sensor faces into the Sun). Diamonds indicate the slope-corrected sensor zenith and relative azimuth for the MODIS observations over the SURFRAD site. 
and assuming an optically equivalent grain-size, which is taken to be $250 \mu \mathrm{m}$. The current prototype assumes that the incident radiation is in the form of a collimated beam, and diffuse irradiance is neglected. This assumption is required because the MOD09 atmospheric correction product does not currently provide information on the ratio of direct/diffuse irradiance used in the atmospheric correction. Figure 2 illustrates ARFs for a solar zenith angle of $70^{\circ}$, which approximates the solar zenith angles corresponding to those over the SURFRAD site at the time of image acquisition.

The anisotropic correction developed using DISORT is only applicable in areas where snow is expected to be the dominant surface in a MODIS pixel. However, much of the seasonally snow-covered area of the world is forested. For example, in North America nearly $40 \%$ of the snow-covered area between November and April is found in forests (Hall and others, 2001). Unfortunately, BRDF measurements and models for snowcovered canopies are lacking, so in the current prototype the $\mathrm{ARF}$ correction is only applied to non-forested areas, whereas snow-covered forests are assumed to be Lambertian reflectors. In the future, the BRDFs from the MOD43 BRDF/albedo product can be used for snow-covered forests.

In the prototype, the anistropic correction is implemented as follows. Look-up tables (LUTs) of ARF values for all potential combinations of solar and sensor zenith angles and relative azimuths between the sensor and the sun are created using DISORT. These LUTs can be updated as improved anisotropic correction factors become available. A global $1 \mathrm{~km}$ land-cover map (Loveland and Belward, 1997) is used to distinguish forested from non-forested areas. In the future, a MODIS land-use/land-cover (LULG) product (MOD12) will replace this product. For forested areas, only a slope correction accounting for slope-induced variations in incident radiation is performed. For non-forested areas the anisotropic correction is performed by taking into account local slope and aspect. In both instances, the slope and aspect of $1 \mathrm{~km}$ pixels is calculated from the Global 30 Arcsecond (GTOPO30) digital elevation model (DEM) using a best-fit plane to all elevations in a $3 \times 3$ pixel moving window.

After correction for anistropic scattering effects, a spectral (narrowband) albedo for each of the seven MODIS bands is determined and then combined into a spectrally integrated broadband albedo. Two approaches for converting MODIS spectral albedo measurements to broadband albedos have been formulated and are currently under consideration for use in the production version of the snow albedo algorithm.

Liang and others (1999) have developed a set of linear combinations designed to produce three broadband landsurface albedos using the seven MODIS land-surface narrowband inherent albedos produced from the MODIS BDRF product (MOD43) (Lucht and others, 2000). An inherent surface albedo is independent of atmospheric state, whereas an apparent albedo is that observed under specific atmospheric conditions. The coefficients developed by Liang and others (1999) were created using approximately 100 spectra, including some of snow, and provide for three inherent broadband albedo measures: one in the visible $(0.4-0.7$ $\mathrm{mm})$, a second in the near-IR $(0.7-5.0 \mathrm{~mm})$ and a third in the shortwave $(0.25-5.0 \mathrm{~mm})$ wavelengths. This research considers only the shortwave albedo measure.

Several sets of coefficients relating various MODIS band combinations to broadband albedo measurements specific to snow-covered surfaces have been developed by one of the authors (J. C. Stroeve). These were constructed by regressing MODIS narrowband albedos, constructed from in situ spectral albedo measurements, to simultaneous measurements of broadband albedo made on the Greenland ice sheet.

\section{STUDY AREA}

Validation of the MODIS snow albedo retrievals was undertaken using data collected at the U.S. National Oceanic and Atmospheric Administration's (NOAA) Fort Peck SURFRAD site (Fig. 3). SURFRAD sites are designed to support climatic research by providing a consistent and accurate long-term record of the surface radiation budget at several locations across the United States. The Fort Peck SURFRAD station is located on the Fort Peck Tribes Reservation in northeastern Montana $\left(48.31^{\circ} \mathrm{N}, 105.10^{\circ} \mathrm{W}\right)$. The SURFRAD data used in

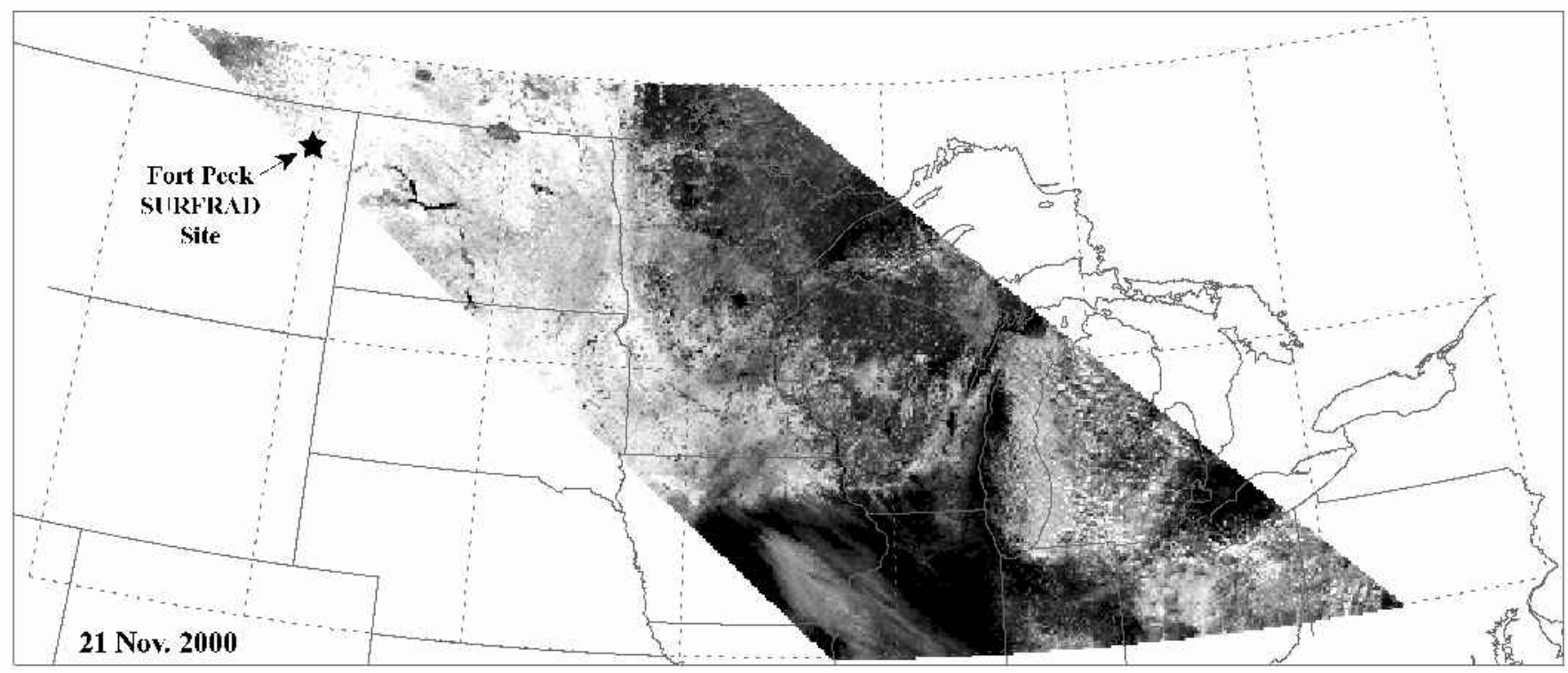

Fig. 3. MODIS band 1 spectral albedo image for 21 November. The Level 2 G MODIS data used in this study are in a specially designed MODIS ISIN equal-area map projection (MODIS ISIN tile h11, v4), but have been placed for display purposes in Albers equal-area conic projection. A star indicates the location of the Fort Peck SURFRAD site. 
this research are available in near-real time from www.ssrb. noaa.gov.

Surface albedo measurements at the SURFRAD site were obtained by ratioing upwelling and downwelling radiance measured from two Epply Precision Spectral pyranometers that cover the spectral interval $0.280-3.00 \mu \mathrm{m}$. Data are reported as $3 \mathrm{~min}$ averages of $1 \mathrm{~s}$ samples. All data produced by the SURFRAD network are considered provisional, though NOAA's Surface Radiation Research Branch does perform some quality control, including automated control procedures, during the processing of daily data. The pyranometers are nominally calibrated on a yearly basis at the National Renewable Energy Laboratory (NREL) (ftp://www.srrb. noaa.gov/ pub/data/surfrad/Fort_Peck.MT/README).

\section{STUDY PERIOD}

The study period covers 6 days from 21 to 26 November 2000. Operational snow-cover maps produced by the U.S. National Operational Hydrologic Remote Sensing Center (NOHRSG) indicated cloud-free and snow-covered conditions prevailed over eastern Montana during much of the period. Temperatures at the Fort Peck site (Fig. 4) were below freezing from 21 to 23 November, rose above freezing on the 24 th, but fell below freezing again on the 25 th. Thus, little melting is expected to have occurred and snow albedos should have remained relatively unchanged, which is confirmed by the radiation measurements. Plots of downwelling and upwelling solar radiation (Fig. 5) reveal that clear skies prevailed for the period 21-25 November. On 26 November, cloud cover was prevalent at the site throughout the day, which is useful in assessing the performance of the cloud mask.

\section{RESULTS AND DISGUSSION}

Comparison of the MODIS snow albedo retrievals with SURFRAD broadband measurements provides the initial opportunity to validate snow albedo retrievals from the prototype MODIS snow albedo algorithm. To perform the comparisons, the MODIS snow albedo algorithm was run on MODIS images acquired over the SURFRAD site for the study period 21-26 November, with five narrow-tobroadband conversion schemes implemented. The initial

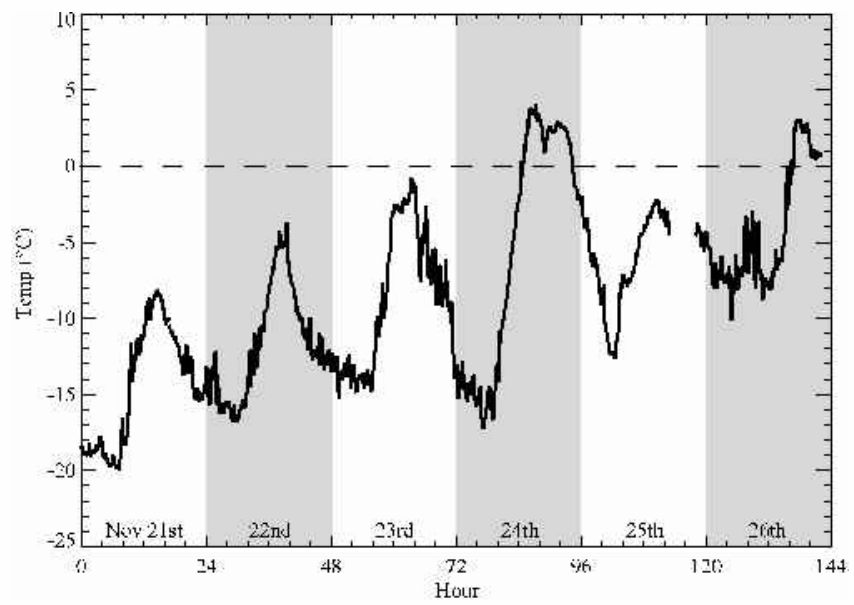

Fig. 4. Air temperature at the Fort Peck SURFRAD site, 21-26 November 2000.

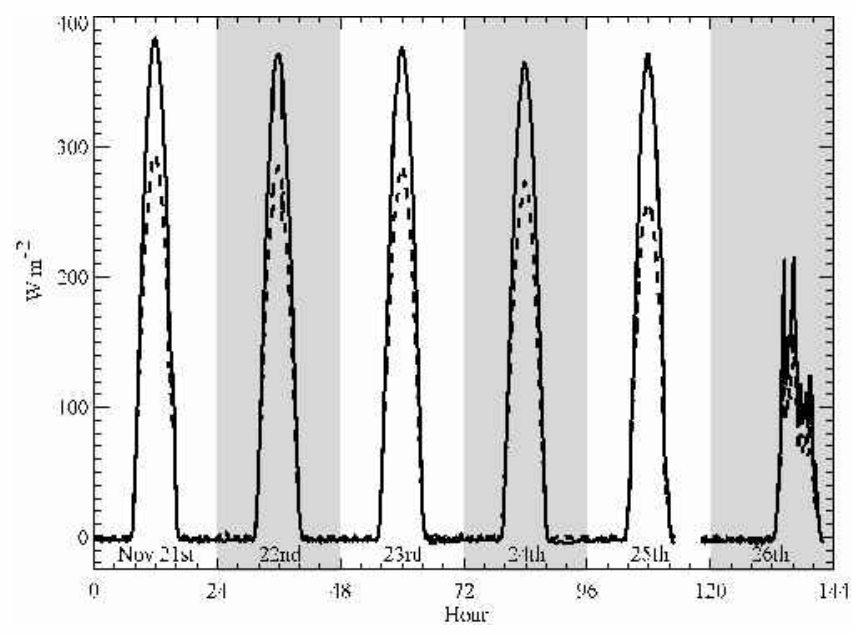

Fig. 5. Downwelling (solid line) and upwelling (dashed line) solar radiation at the Fort Peck SURFRAD site, 21-26 November 2000.

comparisons with in situ observations are encouraging, but improvements to the prototype algorithm are possible.

\section{Narrowband albedos}

Unfortunately, the instrumentation at the Fort Peck SURFRAD does not provide spectral albedo measurements that can be compared to the retrieved MODIS narrowband albedos. However, it is possible to examine how the algorithm adjusts these atmospherically corrected surface reflectances to gain some insight into how the anisotropic correction affects the narrowband albedo retrievals. This is aided by the flatness of the Fort Peck site which has a DEM-derived slope and aspect of $0.3^{\circ}$ and $81^{\circ}$, respectively, which limits the influence of slope and aspect on narrowband albedo retrievals.

For the first 3 days of the study period (Fig. 6), the narrowband albedos are higher than the atmospherically corrected surface reflectances at all wavelengths. On 21 November, this leads to physically unrealistic narrowband albedo values $(>1)$ in the near-IR (MODIS band 4 ). The increase in the narrowband albedos over their atmospherically corrected surface reflectance counterparts occurs because the ARFs are $<1$ (Fig. 2). As the forward scattering of snow is

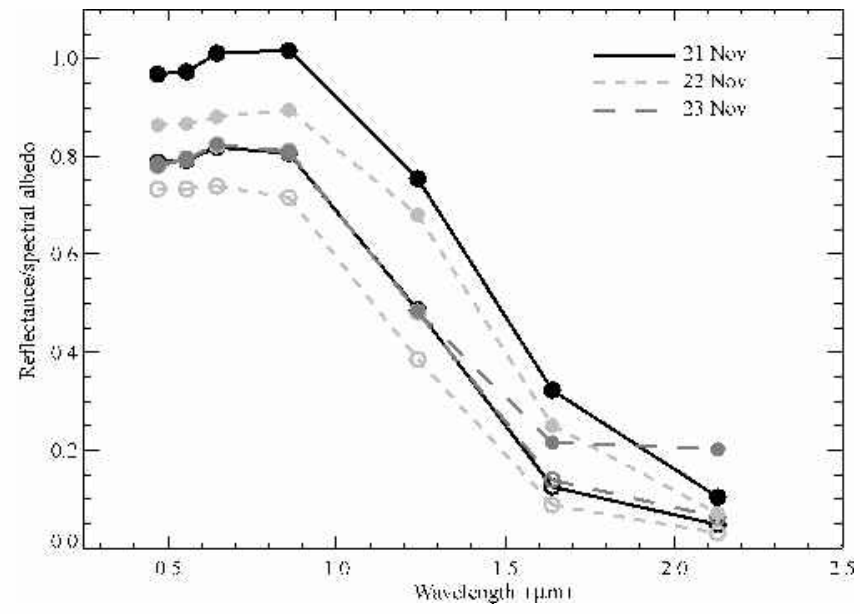

Fig. 6. Atmospherically corrected surface reflectances (open circles and dashed lines) and derived spectral albedos (solid circles and solid lines) over the Fort Peck SURFRAD site, 21-23 November 2000. 
greatest in the shortwave IR bands, the correction is greatest for MODIS bands 6 and 7 .

\section{Broadband albedo}

Initial evaluation of the MODIS snow-mapping algorithm rests on comparison of MODIS broadband albedo retrievals with measured in situ broadband albedos. It is, however, envisioned that the broadband albedos are more important than the narrowband albedos for most applications. Inherent in all comparisons is the assumption that the in situ point measurements are representative of the entire $1 \mathrm{~km}^{2}$ MODIS pixel. Differences between the in situ measurement and the MODIS retrievals may be real, or may simply represent real differences in surface albedo within the MODIS pixel covering the SURFRAD site. In addition, the spectral interval covered by the broadband conversions of Liang and others (1999) is slightly different than the wavelengths to which the Epply Spectral pyranometers are sensitive.

Comparisons of the MODIS broadband retrievals and in situ measurements are presented in Figure 7 and Tables 1 and 2. Overall, the MODIS retrievals are close to, but not identical to, the in situ measurements. The maximum daily difference between the five MODIS broadband albedo retrievals and in situ albedo during the five clear days (21-25 November) was $15 \%$ (Table 2). Daily differences between the "best" MODIS broadband measurement and in situ albedo were $1-8 \%$. These differences are of the same magnitude as differences between in situ measurements and albedo retrievals for the Greenland ice sheet using data from the Advanced Very High Resolution Radiometer (Knap and Oerlemans, 1996; Stroeve and others, 1997). However, no single narrow-tobroadband conversion scheme consistently provided the retrieval closest to the in situ measurement.

The average of the absolute differences between the MODIS retrievals and in situ measurements for the five clear days was $5.0-8.2 \%$. Simple average differences ranged from $-8.2 \%$ to $0.8 \%$ (Table 2 ). Overall, the Liang and others (1999) coefficients provided slightly better albedo retrievals than the Greenland observation-based coefficients. With the exception of 23 November, the Greenland-based coefficients lead to overestimation of snow albedo at the Fort Peck site (Fig. 7).

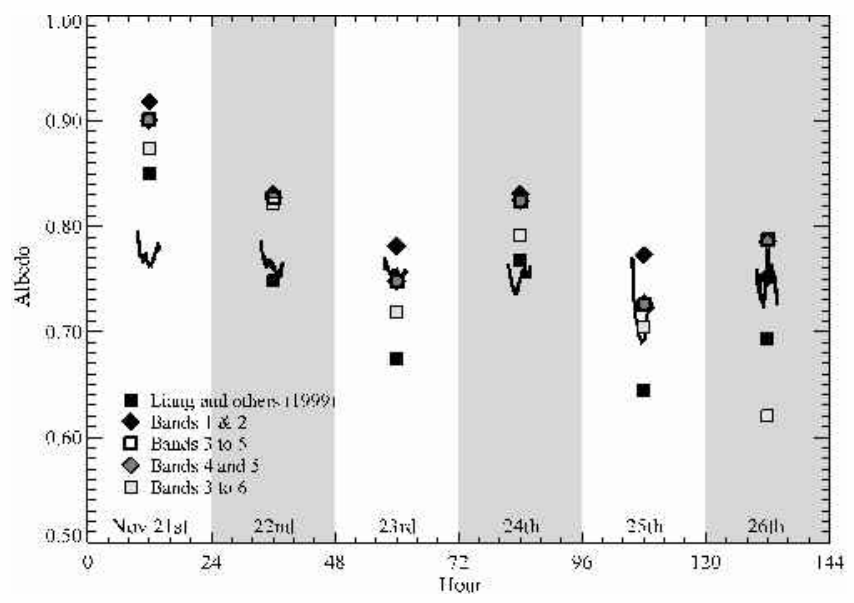

Fig. 7. Comparison of MODIS broadband albedos and in situ SURFRAD albedos. Solid lines represent in situ albedo measurements for solar zenith angles $\leq 75^{\circ}$. The symbols indicate the retrieved MODIS albedos from the pixel corresponding to the SURFRAD site.
Table 1. Summary of albedo estimates from SURFRAD and MODIS and associated viewing geometries

21 Nov 22 Nov $23 \mathrm{Nov} 24 \mathrm{Nov} 25 \mathrm{Nov} 26 \mathrm{Nov}$

\begin{tabular}{lrrrrrr}
\hline SURFRAD albedo $^{1}$ & 0.77 & 0.76 & 0.75 & 0.75 & 0.70 & 0.76 \\
$\begin{array}{l}\text { Liang and others (1999) } \\
\quad \text { albedo }\end{array}$ & 0.85 & 0.75 & 0.67 & 0.77 & 0.65 & 0.69 \\
Bands 1 and 2 albedo & 0.92 & 0.83 & 0.78 & 0.83 & 0.77 & 0.75 \\
Bands 3-5 albedo & 0.90 & 0.83 & 0.75 & 0.83 & 0.73 & 0.79 \\
Bands 4 and 5 albedo & 0.90 & 0.83 & 0.75 & 0.82 & 0.73 & 0.79 \\
Bands 3-6 albedo & 0.87 & 0.82 & 0.72 & 0.79 & 0.71 & 0.62 \\
Solar zenith $\left({ }^{\circ}\right)$ & 69.93 & 68.80 & 68.97 & 69.47 & 69.23 & 70.24 \\
Sensor zenith $\left({ }^{\circ}\right)$ & 49.99 & 6.46 & 54.55 & 13.33 & 45.29 & 30.95 \\
Relative azimuth $\left(^{\circ}\right)$ & 68.24 & 106.37 & 106.19 & 71.19 & 106.26 & 69.58 \\
& & & & & &
\end{tabular}

${ }^{1}$ The SURFRAD albedo represents the daily albedo average for all observations where the solar zenith angle was $\leq 70^{\circ}$.

The broadband albedo retrievals with the poorest fit to the in situ measurements are those derived from the narrow-tobroadband conversion based on only MODIS bands 1 and 2 . This is perhaps not surprising, since as was pointed out by Hall and others (1989), it is best to use the full shortwave spectrum in the calculation of snow albedo since the reflectance of snow is low in the shortwave IR. As is apparent in Figure 7, considerable scatter exists between the broadband albedo retrievals produced by the different conversion schemes. Overall, the scatter is on the order of $10 \%$ and is of the same magnitude as the differences in MODIS estimates from the in situ measurements. This also illustrates the potential for errors of a few per cent in the retrieved albedo due to the narrow-to-broadband conversion, which has also been noted for the MOD43 products (Lucht and others, 2000).

The existing prototype algorithm produces broadband albedos generally within $10 \%$ of those measured at the Fort Peck site. Overall, there is a tendency for the snow albedo algorithm to overestimate albedo over the five clear days during the study period. This may be because the anisotropic reflectance corrections produce unrealistically high spectral albedos. Unfortunately, testing this hypothesis is not currently possible, making comparisons of MODIS narrowband spectral reflectances with field observations an important area for future validation efforts. Implementation of the anisotropic correction in the MODIS snow albedo algorithm will be via a LUT, so any alterations to

Table 2. Albedo differences between in situ SURFRAD measurements and MODIS broadband albedo retrievals, 21-25 November

\begin{tabular}{lccccc}
\hline Date & $\begin{array}{c}\text { Liangand others } \\
\text { (1999) }\end{array}$ & $\begin{array}{c}\text { Bands } \\
\text { 1 and 2 }\end{array}$ & $\begin{array}{c}\text { Bands } \\
3-5\end{array}$ & $\begin{array}{c}\text { Bands } \\
\text { 4 and 5 }\end{array}$ & $\begin{array}{c}\text { Bands } \\
3-6\end{array}$ \\
\hline $21 \mathrm{Nov}$ & -0.083 & -0.151 & -0.134 & -0.133 & -0.107 \\
$22 \mathrm{Nov}$ & 0.014 & -0.069 & -0.066 & -0.065 & -0.059 \\
$23 \mathrm{Nov}$ & 0.081 & -0.027 & 0.007 & 0.006 & 0.036 \\
$24 \mathrm{Nov}$ & -0.021 & -0.084 & -0.078 & -0.077 & -0.045 \\
$25 \mathrm{Nov}$ & 0.050 & -0.078 & -0.031 & -0.032 & -0.009 \\
Average difference & 0.008 & -0.082 & -0.060 & -0.060 & -0.037 \\
Average of absolute & 0.050 & 0.082 & 0.063 & 0.063 & 0.051 \\
differences & & & & & \\
\end{tabular}

Note: The in situ values represent the daily albedo average observations where the solar zenith angle was $\leq 70^{\circ}$. 
the anisotropic correction are easily accommodated. Additional research is also required before a single narrow-tobroadband conversion scheme can be adopted.

\section{Gloud-masking problems}

Part of the algorithm development process is to identify problems with MODIS inputs to the prototype algorithm. All MODIS inputs used in this research are considered provisional and may well undergo future modifications. One ongoing problem, faced by both the MODIS snow albedo and the snow-mapping algorithms, is cloud discrimination over snow-covered surfaces. Over the study period, the cloud information contained within the surface reflectance quality dataset (MOD09GST) incorrectly flagged that the "best" observation over the Fort Peck site was cloud-covered for the period 21-23 November. However, in situ measurements indicate clear conditions existed during this period (Fig. 5). Cloud masking remains a potential problem and may make it necessary to calculate a snow albedo regardless of cloud conditions and then provide cloud information in a data quality.

\section{Temporal compositing}

The rapidity with which the albedo of a snow-covered surface can change precludes estimating snow albedo using observations acquired over a 16 day period as is done in the MOD43 products. However, as albedo maps for the study period indicate (Fig. 8), persistent cloud cover is a severe limitation on producing a global daily snow albedo product.
While the actual compositing method has not been determined, it is envisioned that the daily snow albedo products will be combined to create an 8 day snow albedo product that will complement the existing 8 day snow-cover product. Temporal compositing should enable creation of a more useful snow albedo product.

\section{GONGLUSIONS AND FUTURE DIREGTIONS}

The MODIS snow albedo algorithm is still evolving and this research represents only initial validation of the developing algorithm's performance. Work to date has focused on the creation of a working prototype algorithm. Overall, the algorithm appears to be working as was envisioned. However, this initial work highlights several areas where future refinements and validation of the algorithm's performance are necessary.

First, in situ spectral albedo measurements made contemporaneously with MODIS overpasses are required to validate the narrowband spectral albedos. Given that corrections for anisotropic scattering can lead to large adjustments to the atmospherically corrected surface reflectances, especially in the shortwave IR (Fig. 6), further validation of the spectral albedos is prudent, with adjustments made to the anisotropic reflectance corrections as required. It may also be necessary to assess the sensitivity of the retrievals to the grain-size and ratio of direct/diffuse irradiance assumed in the DISORT modeling.

Second, assessment of the potential errors in the MODIS albedo algorithm due to limitations in the atmosphere
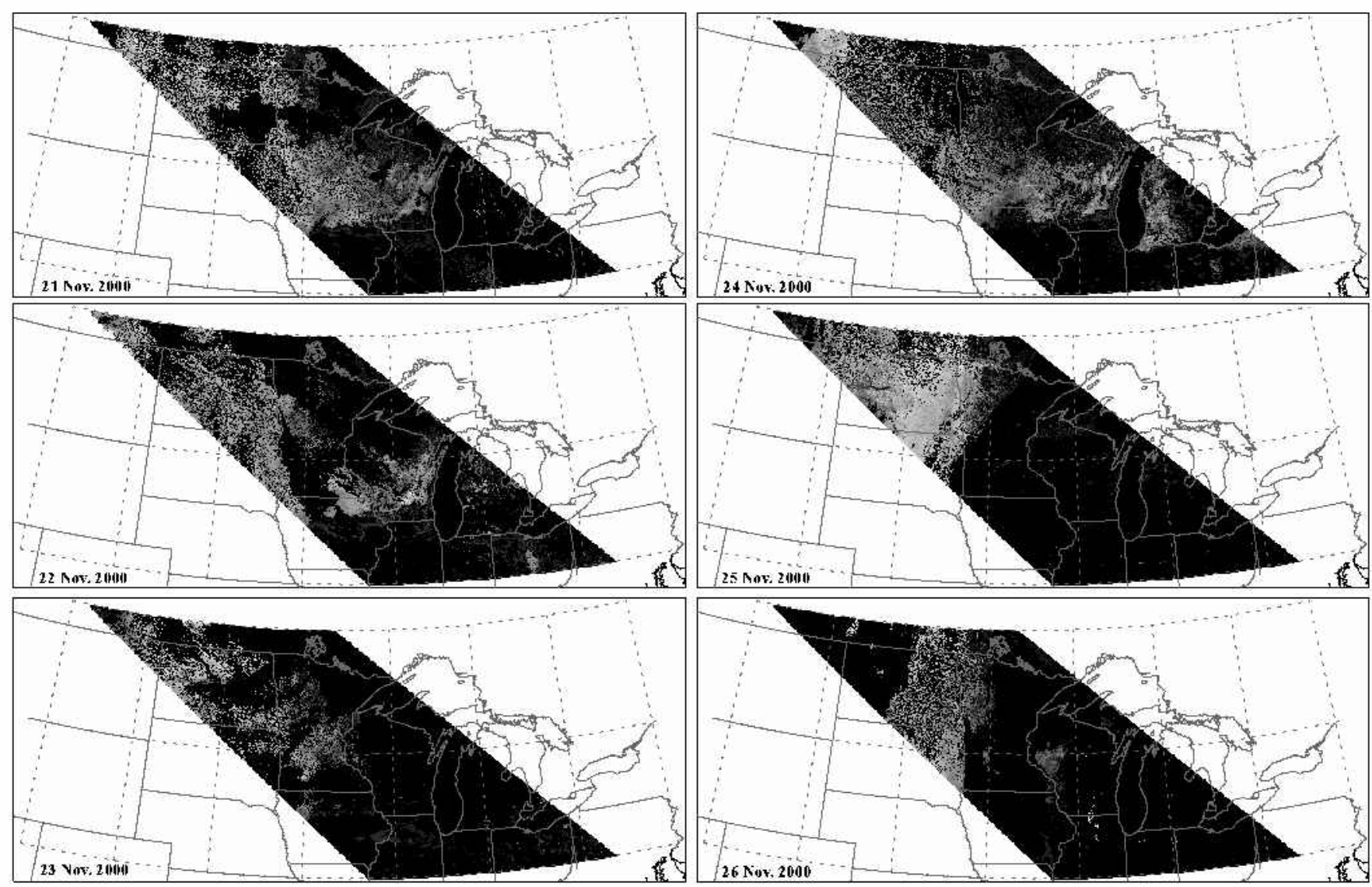

Snow alliedo

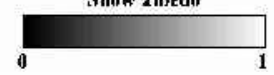

Fig. 8. Snow albedo over the Midwestern United States, 21-26 November 2000.. The images use the Liang and others (1999) narrow-to-broadband conversions. Pixels identified with partial or greater cloud cover in the MOD09 surface reflectance have been masked out, which probably results in some clear areas being excluded. 
correction on snow albedo is required. While the algorithm development research to date has not directly addressed the problem of atmospheric correction over snow, it is being addressed within the larger MODIS snow- and ice-mapping program. A validation study of the effects of atmospheric correction on albedo retrievals of snow from both MODIS and MISR has been funded as part of the Terra MODIS Land Product Validation (see http://www-nsidc.colorado.edu/ PROJECTS/ALBEDO/ for a project description).

Third, further investigation into the MODIS narrow-tobroadband conversion is necessary. It is desirable to develop two empirically based narrow-to-broadband conversion schemes specifically for snow. The first scheme should utilize all seven MODIS land-surface bands. A second scheme should utilize a subset of bands excluding the shortwave IR bands (bands $5-7$ ). This second set of conversion coefficients may unfortunately be required because of potential striping problems in the shortwave IR band aboard the Aqua MODIS instrument (personal communication from D. K. Hall, 2001).

Validation of the MODIS snow albedo algorithm will continue at the Fort Peck site and is also planned using sites in Greenland where concurrent meteorological measurements from the Program for Arctic Regional Climate Assessment (PARCA) Greenland Climate Network (GCNet) automated weather stations are available. These ongoing validation efforts will enable refinement of the existing MODIS snow albedo algorithm.

\section{ACKNOWLEDGEMENTS}

The authors would like to thank A.W. Nolin of CIRES for discussions on snow albedo and atmospheric correction over snow. G. A. Riggs and N. Digiolamo provided valuable assistance with the MODIS Level $2 \mathrm{G}$ products. This research was supported by NASA grants NAG5-8137 and NAG5-9455.

\section{REFERENGES}

Ackerman, S. and8 others. 1997. Discriminating clear-sky from clouds with MODIS. Greenbelt, MD, U.S. National Aeronautics and Space Administration. (Algorithm Theoretical Basis Document MOD35; http://modis.gsfc. nasa.gov/MODIS/Data/ATBDs/atbd_mod06.pdf.)

Barbieri, R. and 6 others. 1997. Draft of the MODIS level $1 B$ algorithm theoretical basis document. Version 2.0. Greenbelt, MD, U.S. National Aeronautics and Space Administration. (Algorithm Theoretical Basis Document MOD01; http://modis.gsfc.nasa.gov/MODIS/Data/ATBDs/atbdmod01.pdf

Barnett, T. P., L. Dümenil, U. Schlese, E. Roeckner and M. Latif. 1989. The effect of Eurasian snow cover on regional and global climate variations. 7. Atmos. Sci., 46(5), 661-685.

De Abreu, R. A., J. Key, J. A. Maslanik, M. C. Serreze and E. F. LeDrew. 1994. Comparison of in situ and AVHRR-derived broadband albedo over Arctic sea ice. Arctic, 47(3), 288-297.

Fily, M., B. Bourdelles, J.-P. Dedieu and C. Sergent. 1997. Comparison of in situ and Landsat thematic mapper derived snow grain characteristics in the Alps. Remote Sensing Environ., 59(3), 452-460.

Hall, D. K., A. T. C. Chang, J. L. Foster, C. S. Benson and W. M. Kovalick. 1989. Comparison of in situ and Landsat derived reflectance of Alaskan glaciers. Remote Sensing Environ., 28(1), 23-31.

Hall, D. K., G. A. Riggs and V.V. Salomonson. 1995. Development of methods for mapping global snow cover using Moderate Resolution Imaging Spectroradiometer (MODIS) data. Remote Sensing Environ., 54(2), 127-140.

Hall, D. K., A. B. Tait, G. A. Riggs, V.V. Salomonson, J.Y. L. Chien and A. G. Klein. 1998. Algorithm Theoretical Basis Document (ATBD) for the MODIS snow-, lake ice- and sea ice-mapping algorithms. Greenbelt, MD, U.S. National Aeronautics and Space Administration. (Algorithm Theoretical Basis Document MOD10; http://modis.gsfc.nasa.gov/MODIS/Data/ATBDs/ atbdmod10.pdf.)

Hall, D. K., J. L. Foster, V.V. Salomonson, A. G. Klein and J.Y. L. Chien. 2001. Development of a technique to assess snow-cover mapping errors from space. IEEE Trans. Geosci. Remote Sensing, GE-39(2), 432-438.

Jin, Z. and J. J. Simpson. 2000. Bidirectional anisotropic reflectance of snow and sea ice in AVHRR channel 1 and 2 spectral regions. Part II. Correction applied to imagery of snow on sea ice. IEEE Trans. Geosci. Remote Sensing, GE-38(2), 999-1015.

Klein, A. G. and D. K. Hall. 1999. Snow albedo determination using the NASA MODIS instrument. Proc. East. Snow Conf., 55th Annual Meeting, 2-4 June 1999, Fredericton, New Brunswick, Canada, 77-85.

Klein, A. G., D. K. Hall and G. A. Riggs. 1998. Improving snow-cover mapping in forests through the use of a canopy reflectance model. Hydrol. Processes, 12 , $1723-1744$.

Klein, A. G., D. K. Hall and A. W. Nolin. 2000. Development of a prototype snow albedo algorithm for the NASA MODIS instrument. Proc. East. Snow Conf., 57th Annual Meeting, 17-19 May 2000, Syracuse, New York, 143-157.

Knap, W. H. and J. Oerlemans. 1996. The surface albedo of the Greenland ice sheet: satellite-derived and in situ measurements in the Søndre Strømfjord area during the 1991 melt season. f. Glaciol., 42(141), 364-374

König, M., J.-G. Winther and E. Isaksson. 2001. Measuring snow and glacier ice properties from satellite. Rev. Geophys., 39(1), 1-28.

Kukla, G. 1981. Climatic role of snow covers. International Association of Hydrological Sciences Publication 131 (Symposium at Canberra $1979-$ Sea Level, Ice and Climatic Change), 79-107.

Liang, S., A. H. Strahler and C.W. Walthall. 1999. Retrieval of land surface albedo from satellite observations. 7. Appl. Meteorol., 38(6), 712-725.

Lindsay, R.W. and D. A. Rothrock. 1994. Arctic sea ice albedo from AVHRR. 7. Climate, 7 (11), 1737-1749.

Loveland, T. R. and A. S. Belward. 1997. The IGBP-DIS global $1 \mathrm{~km}$ land cover data set, DESCover: first results. Int. F. Remote Sensing, 18(15), 3289-3295.

Lucht, W., A. H. Hyman, A. H. Strahler, M. J. Barnsley, P. Hobson and J. P. Muller. 2000. A comparison of satellite-derived spectral albedos to ground-based broadband albedo measurements modeled to satellite spatial scales for a semidesert landscape. Remote Sensing Environ., 74(1), 85-98.

Nicodemus, F. E., J. J. Hsia, J. J. Richmond, I. W. Ginsberg and T. Limperis. 1977. Geometrical considerations and nomenclature for reflectance. Gaithersburg, MD, U.S. Department of Commerce. National Bureau of Standards. (Technical Report Monograph 160.)

Nolin, A.W. and J. Stroeve. 1997. The changing albedo of the Greenland ice sheet: implications for climate modeling. Ann. Glaciol., 25, 51-57.

O'Neill, A. D. J. and D. M. Gray. 1973. Spatial and temporal variations of the albedo of a prairie snowpack. International Association of Scientific Hydrology Publication 107 (Symposium at Banff 1972 - The Role of Snow and Ice in Hydrology), Vol. 1, 176-186.

Reijmer, C. H., W. H. Knap and J. Oerlemans. 1999. The surface albedo of the Vatnajökull ice cap, Iceland: a comparison between satellite-derived and ground-based measurements. Boundary-Layer Meteorol., 92(1), 125-144.

Riggs, G. A., D. K. Hall and S. A. Ackerman. 1999. Sea ice extent and classification mapping with the Moderate Resolution Imaging Spectrometer Airborne Simulator (MAS). Remote Sensing Environ., 68 (2), 152-163.

Robinson, D. A. and G. Kukla. 1985. Maximum surface albedo of seasonally snow-covered lands in the Northern Hemisphere. f. Climate Appl. Meteorol., 24(5), 402-411.

Stamnes, K., S.-C. Tsay, W. Wiscombe and K. Jayaweera. 1988. Numerically stable algorithm for discrete-ordinate-method radiative transfer in multiple scattering and emitting layered media. Appl. Opt., 27(12), 2502-2509.

Stroeve, J., A. Nolin and K. Steffen. 1997. Comparison of AVHRR-derived and in situ surface albedo over the Greenland ice sheet. Remote Sensing Environ., 62(3), 262-276.

Vermote, E. F. and A. Vermeulen. 1999. Atmospheric correction algorithm: spectral reflectances MOD09. Greenbelt, MD, U.S. National Aeronautics and Space Administration. (Algorithm Theoretical Basis Document MOD08; http://modis.gsfc.nasa.gov/MODIS/Data/ATBDs/atbdmod08.pdf)

Winther, J.-G. 1993a. Landsat TM derived and in situ summer reflectance of glaciers in Svalbard. Polar Res., 12(1), 37-55.

Winther, J.-G. 1993b. Short- and long-term variability of snow albedo. Nord. Hydrol., 24(2-3), 199-212. 